\title{
Conditional Handicaps in Exuberant Lizards: Bright Color in Aggressive Males Is Correlated with High Levels of Free Radicals
}

\author{
Christopher R. Friesen ${ }^{1 *}$, Mark R. Wilson ${ }^{2}$, Nicky Rollings ${ }^{1}$, Joanna Sudyka ${ }^{3}$, \\ Camilla M. Whittington ${ }^{1}$, Mathieu Giraudeau ${ }^{4,5}$ and Mats Olsson ${ }^{6}$
}

${ }^{1}$ School of Life and Environmental Sciences, University of Sydney, Sydney, NSW, Australia, ${ }^{2}$ School of Biological Sciences, University of Wollongong, Wollongong, NSW, Australia, ${ }^{3}$ Institute of Environmental Sciences, Jagiellonian University, Kraków, Poland, ${ }^{4}$ School of Life Sciences, Arizona State University, Tempe, AZ, USA, ${ }^{5}$ Centre for Ecology and Conservation, College of Life and Environmental Sciences, University of Exeter, Penryn, UK, ${ }^{6}$ Department of Biological and Environmental Sciences, University of Gothenburg, Gothenburg, Sweden

OPEN ACCESS

Edited by:

David Costantini,

University of Antwerp, Belgium

Reviewed by:

Luis M. San-Jose,

University of Lausanne, Switzerland

Stefania Casagrande,

Max Planck Institute for Ornithology,

Germany

*Correspondence:

Christopher R. Friesen

christopher.friesen@sydney.edu.au

Specialty section:

This article was submitted to Behavioral and Evolutionary Ecology,

a section of the journa

Frontiers in Ecology and Evolution

Received: 18 June 2016

Accepted: 16 January 2017

Published: 01 February 2017

Citation:

Friesen CR, Wilson MR, Rollings $N$,

Sudyka J, Whittington CM,

Giraudeau M and Olsson M (2017)

Conditional Handicaps in Exuberant

Lizards: Bright Color in Aggressive

Males is Correlated with High Levels of

Free Radicals. Front. Ecol. Evol. 5:1.

doi: 10.3389/fevo.2017.00001
The maintenance of genetic variation and signal honesty may be explained, in part, through the genic capture hypothesis in sexual selection biology. Polygenic traits, like body condition, could help maintain variation in signaling traits under strong, directional sexual selection while maintaining signal honesty. Here we consider the genic capture hypothesis in a study of morph-specific condition and free radical effects on signaling traits (head coloration) in males of a polymorphic lizard, the Australian painted dragon (Ctenophorus pictus). Males differ in head color (red, orange, yellow, and a "blue" morph that has no yellow or red pigments). The red and yellow morphs were the first described and we have previously demonstrated that red morphs are aggressive and dominant over yellow morphs that are better at sperm completion than the red morphs. Body condition varied significantly in its relationship with superoxide among the four morphs, with males in better condition showing higher superoxide levels in "yellow-orange-reds" morphs (least so in red morphs). Blue morphs contrasted markedly by showing lower superoxide levels in males in better condition, perhaps facilitated by no (or reduced) dermal deposition of pigmentation on the head. Color degradation with loss in condition from yellow to red morphs, suggesting that red morphs are better able to maintain color with superoxide acting as a potential handicap. This result is consistent with conditiondependent signal expression and the genic capture hypothesis; males with the more pronounced signal carry a higher potential cost (higher superoxide levels) when being in better body condition, while maintaining more vivid coloration (the condition-dependent trait).

Keywords: ROS, superoxide, body condition, polymorphic species, color maintenance

\section{INTRODUCTION}

Genic capture supposes that trait expression depends on overall condition (Rowe and Houle, 1996). Overall condition is determined by many loci throughout the genome, which makes for a large mutation target, allowing new mutations to keep pace with erosion by selection (Kodric-Brown and Brown, 1984; Rowe and Houle, 1996; Tomkins et al., 2004; Kotiaho et al., 2008). Body condition 
reflects the efficient collection, assimilation and deployment of resources, and depends on the individual's capacity to cope with handicaps like infection, injury, parasitism, and environmental stress throughout ontogeny (Zahavi, 1975; Andersson, 1982; Hamilton and Zuk, 1982; Folstad and Karter, 1992; Rowe and Houle, 1996; Hill, 2011). Those individuals that can allocate comparatively more resources to the development and maintenance of a colorful display trait, while tolerating concomitant viability costs, are honestly signaling their quality to potential mates and rivals in a condition-dependent manner (Cotton et al., 2004; Velando et al., 2006; Bortolotti et al., 2009). Thus, the condition-dependent honesty of the signal ensures that preference for the signal will persist through evolutionary time (Pomiankowski and Moller, 1995; Lorch et al., 2003; Tomkins et al., 2004; Kotiaho et al., 2008; Bonilla et al., 2016). The physiological efficiency of resource collection and distribution and the capacity to withstand assaults to homeostasis is underpinned by the conditional and environmental regulation and interaction of many genes that differ among individuals in a population (Andersson, 1982; Nur and Hasson, 1984; Rowe and Houle, 1996; Hill, 2011; Chandler et al., 2013; Bonilla et al., 2016).

Color-polymorphic species are a valuable tool in resolving the selective forces involved in condition-dependent sexually selected trait expression in wild populations. Heritable color morphs often have distinct behaviors and physiology, with associated differences in selection pressures on an otherwise common genetic background (Sinervo and Lively, 1996; Pryke and Griffith, 2006; Healey et al., 2007; Pryke et al., 2007; Olsson et al., 2009a, 2007a; reviewed in Huxley, 1955; Wellenreuther et al., 2014). Colorful traits often fade during the breeding season, which suggests these traits may have condition-dependent expression and costly to maintain (Cotton et al., 2004; Grunst et al., 2014; Reinhart et al., 2015), which are potentially mediated by oxidative stress (von Schantz et al., 1999; Monaghan et al., 2009; Hõrak et al., 2010; Garratt and Brooks, 2012; Costantini, 2014; Hung and Li, 2015) and body condition (Slagsvold and Lifjeld, 1992; Costantini, 2008; Stephen Dobson et al., 2008). Reactive oxygen species (ROS) damage DNA, proteins and cell membranes, triggering cell death and color-fading (Dowling and Simmons, 2009; Costantini, 2010; Olsson et al., 2012).

Here we assessed the relationship between a measure of resources (body condition: $\mathrm{BCI}$ ), superoxide levels and the maintenance of head coloration in a wild color-polymorphic lizard. This species, the Australian painted dragon (Ctenophorus pictus), has been the subject of extensive investigations in oxidative stress and sexual selection biology. In our study population, there are four genetically determined male morphs (Figure 1; Red, Orange, Yellow and Blue; Olsson et al., 2012). These morphs fluctuate in frequency across years but at least three (red, yellow, and orange) have been demonstrated to have similar reproductive success in the wild (Olsson et al., 2007a). Morph color is important for social behavior and sexual selection, and most research to date has been conducted on the red and yellow morphs. Red morphs are more aggressive and have higher testosterone than yellow morphs (Healey et al., 2007; Olsson et al., 2007b). Yellow morphs have relatively larger testes than red morphs, which allows them to gain more

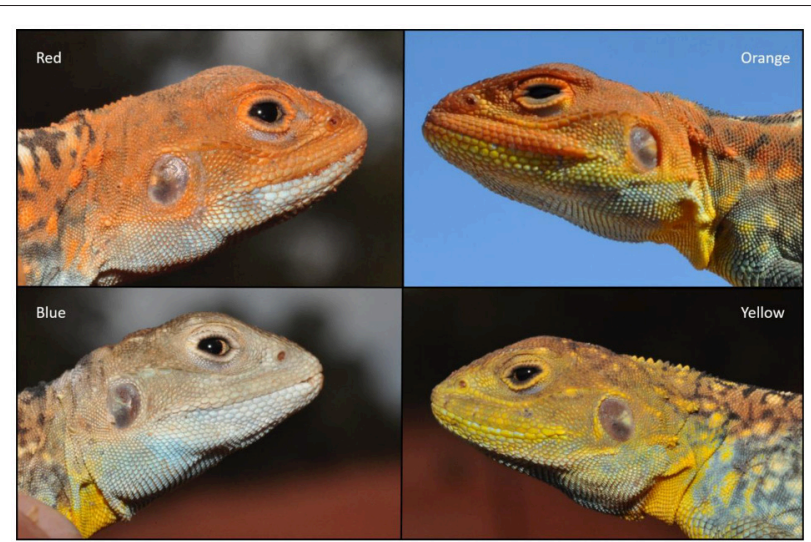

FIGURE 1 | Male Ctenophorus pictus in the Yathong population exhibit four head color morphs (clockwise starting from the upper left): Red; Orange; Yellow; and Blue. Photo by CRF.

than three times greater paternity in direct sperm competition trials against red morphs in the lab (Olsson et al., 2009b). However, this yellow morph advantage in sperm competition does not translate to the field, presumably because red morphs efficiently defend both territories and mates, which precludes sperm competition (Olsson et al., 2009a). Males, regardless of morph, whose territory borders that of a red morph, had lower BCIs relative to those who did not have a red neighbor suggesting red-morph aggression is costly/stressful for his neighbors (Healey and Olsson, 2009). However, red morphs may also pay a cost for their aggressiveness and high testosterone, because non-specific superoxide is higher in red morphs than yellow morphs when mitochondria are maximally active as revealed when manipulated by a biochemical stressor (CCCP) in vitro (Olsson et al., 2009c). Although head color is in part carotenoidbased, dietary manipulation of carotenoids does not mediate a relationship between superoxide and bright colouration (Olsson et al., 2008). Nevertheless, experimental lowering of superoxide using a superoxide dismutase mimetic (EUK 134) reduces color fading over the breeding season (Olsson et al., 2012), suggesting superoxide production is linked to color degradation. Given these differences between the two best described morphs, we might expect different aspects of condition (e.g., BCI and superoxide) to vary among these morphs due to past selection to optimize the different morph-specific reproductive strategies and to be reflected in color-fading sexually active males.

The overarching question in this work is: How do condition and superoxide constrain signal quality on different genetic backgrounds represented by the different morphs?

We focus our predictions on the two morphs for which we have the most information: Yellow and red. Given the relationship between color morph and associated reproductive tactics, superoxide and $\mathrm{BCI}$, we predicted that the red morph with correlated suite of traits forged by an evolutionary history of higher aggression (Healey et al., 2007; Olsson et al., $2007 a, b)$ would have evolved the capacity to better ameliorate a trade-off between body condition and level of superoxide. Furthermore, because territoriality and aggressiveness is costly, 
color maintenance would rely on condition through the breeding season. Thus, yellow morphs are predicted to show a negativeand red morphs a positive-relationship with body condition and color maintenance.

\section{METHODS}

\section{Animal Collection/Husbandry}

Lizards were caught ( $\mathrm{N}=72$, October 2014, 17 Blue, 9 Orange, 20 Red, and 26 Yellow males) at Yathong Nature Reserve, New South Wales $\left(145^{\circ} 35^{\prime} ; 32^{\circ} 35^{\prime}\right)$ and were brought back to holding facilities at the University of Sydney. At capture, male morph type was assigned by eye based on previously established categorizations (Olsson et al., 2007a): While "yellow-" and "red-" morphs were described first based on their head color, "orange" morphs have head-color in between red- and yellow morphs, typically with yellow around their mouth, and a red-orange head color, while blue morphs are males without an obvious head color and seem to lack pigments associated with yellow or red. Nevertheless, morph-assignment by eye is repeatable within and between researchers in the field (Sinervo and Lively, 1996; Olsson et al., 2007a). Individuals were kept individually in tanks $(60 \times$ $60 \times 50 \mathrm{~cm}$ ) and haphazardly assigned to three different rooms on a 12:12 h (light:dark) light regime and were fed crickets and mealworms to satiation.

\section{Superoxide}

On December 16th, 2014 lizards were weighed $( \pm 0.01 \mathrm{~g})$, measured snout-to-vent (SVL; $\pm 1 \mathrm{~mm}$ ), and body condition was calculated as residuals from a mass-SVL regression. At the same time, blood was collected in a capillary tube after gently perforating the vena angularis in the corner of the mouth using a sterile 18 ga. needle. These males were sexually active (i.e., mated with females).

\section{Quantifying Superoxide}

The samples of peripheral blood $(70 \mu \mathrm{l})$ were diluted with 9 volumes of phosphate buffered saline (PBS; $137 \mathrm{mM} \mathrm{NaCl}$, $2.7 \mathrm{mM} \mathrm{KCl}, 1.5 \mathrm{mM} \mathrm{KH} \mathrm{PO}_{4}, 8 \mathrm{mM} \mathrm{Na}_{2} \mathrm{HPO}_{4}, \mathrm{pH} \mathrm{7.4)}$ and stored on ice prior to analyses, which were completed within $4 \mathrm{~h}$ of sampling. Prior to staining, diluted blood was diluted a further 50-fold with PBS and then centrifuged ( $300 \mathrm{~g}$ for $5 \mathrm{~min}$ ) to pellet cells; each cell pellet corresponded to $10 \mu \mathrm{l}$ of whole blood. Cells were resuspended in $100 \mu \mathrm{l}$ of PBS containing $5 \mu \mathrm{M}$ MitoSOX Red (MR; Molecular Probes, Invitrogen, USA). MR was added from stock solutions in dimethylsulfoxide (DMSO); the final concentration of DMSO was $0.2 \%(\mathrm{v} / \mathrm{v})$ or less. Cells were subsequently incubated at $37^{\circ} \mathrm{C}$ for $30 \mathrm{~min}$, then washed with PBS by centrifugation as described above and held on ice until analyzed by flow cytometry; 50,000 events were acquired for all samples. Flow cytometry was performed using a Becton Dickinson LSR II, with excitation at $488 \mathrm{~nm}$ and emitted fluorescence collected using band pass filters of $575+/-$ $13 \mathrm{~nm}$. Data were acquired and analyzed using FACSDiva v4.0.1 (Becton Dickinson, Sydney, Australia) and FloJo (v8.4.6; TreeStar Inc., USA) software, respectively. On the basis of forward angle laser scatter and side angle laser scatter, a number of blood cell populations were discerned; the results obtained were similar for all these populations. For each sample, the arithmetic mean fluorescence for all 50,000 cells acquired was determined using FloJo software and used to compare between samples and treatments. The accuracy of flow cytometry result from samples from the same individuals has been measured in a separate experiment (see Olsson et al., 2008 for further details), involving 14 males with a correlation coefficient between samples of $r=$ 0.97, $(P<0.0001)$. Thus, our flow cytometry technique can be argued to be highly consistent.

\section{Coloration}

Colouration (hue) was quantified at the start of the study period and $>3$ months later (March 26th, 2015) using digital photography, following standard published methods (e.g., McGraw et al., 2002; Oh and Badyaev, 2006; Lendvai et al., 2013). Painted dragon skin does not reflect in the UV, thus techniques that rely on visible-light are sufficient to capture variation in coloration in this species. Using a Nikon D810, two separate photographs were taken of the left side of the head at each time point in standardized conditions and digital images were imported into Adobe Photoshop to extract hue, brightness and saturation values (in the HSB color space). Because Photoshop assigns hue values around a $360^{\circ}$ color wheel, with red set at 0 , higher hue scores denote more yellow individuals. Thus, positive values in the change of coloration during this period reflect a decrease in coloration while negative values reflect an increase in coloration during period. To visualize the correlation between coloration and condition on the same scale (negative to positive), we plotted color data in two ways, as raw data (Figure 3A), and as the relationship between body condition and the inverse of Photoshop color scores (Figure 3B), which we find a somewhat more intuitive relationship to interpret (thus, a higher inverse value represents a more vivid color). Values for the two images of each lizard/time point were averaged for statistical analyses (repeatability $=0.99$, Aitken et al., 1989).

\section{Statistics}

Data were analyzed using SAS 9.4 with all analyses performed on raw Photoshop data. We used generalized linear mixed models to: (1) assess the relationship (i.e., interaction) between superoxide and morph with body condition as a covariate, and (2) assess the relationship (i.e., interaction) between morph, body condition and final colouration (initial coloration was included as a covariate to account for individual differences in hue). Our analyses target among-morph differences in the relationships between our response variables, superoxide and coloration, and body condition. Thus, we are specifically looking for effects at the interaction level between these parameters. We included the room where the lizards were housed as a random factor in each model to account for any undetected differences in environmental factors that might affect metabolism, superoxide production or body condition. Flow cytometry analysis is consistent and robust within, but not among, sampling bouts, we therefore report ROS data from the onset but not as a difference between the onset and the end of the study period. Coloration is the net outcome of a time-dependent process, not of a spot 
reading of a parameter, such as condition, that is assessed at the same time color is measured. The time lag in color change, compared to other phenotypic traits that modifies color, would strongly argue that earlier measurements are much more likely to accurately predict color at the end of this process.

\section{RESULTS}

The interaction effects between condition and superoxide, and between condition and coloration, were significant and we therefore refrain from further reporting and discussing lower level effects (such as morph differences in response variables; Supplemental Material).

\section{Superoxide}

The relationship between superoxide levels and body condition depended on morph [morph $\mathrm{x}$ condition: $F_{(3,64)}=3.82, P=$ $0.014]$. When the significant morph-condition interaction was evaluated in a comparison between morphs with the yellow morph set to zero, the red and blue morphs showed a significantly lower slope effect of condition on level of superoxide than did yellow morphs, whereas orange morphs were not significantly different to yellow, baseline morphs. However, importantly, whereas males in the yellow-red spectrum showed an increase in superoxide levels with elevated condition, blue morphs exhibited relatively less superoxide with increasing condition (Figure 2). The baseline level (yellow morph) set to zero by the SAS software were tested separately for a relationship between condition and superoxide level, which was confirmed to be significant and positive $(\beta=0.72 \pm 0.21$, SE, $P=0.002, n=26$; Table 1). Thus, in summary, yellow morphs suffer from a steeper increase in superoxide with higher body condition index. Blue morphs (i.e., lacking in yellow-red skin pigmentation), is the only morph showing lower levels of superoxide when in better body condition.

\section{Coloration}

We first ran univariate analyses of relationships between hue measurements at the end of the season (response variable) and the beginning of the season (predictor). Interestingly, this relationship was significant for all males in the yellow-red spectrum (regression coefficients, $\beta=0.59-0.84,0.0003<P<$ 0.0001 ), that is, more colorful males early in the season are also more colorful toward the end of the mating season, whereas blue morph coloration at the end of the study period was unrelated to that at the beginning of the study period $(\beta=0.047, P=0.788)$.

In the combined data set, Hue was significantly affected by the interaction between morph and body condition $(F=$ 3.38, $P=0.0237$ ). Thus, the morphs differed in how well they maintained head color at elevated body condition (i.e., significant morph $\mathrm{x}$ condition interactions; Table 2). Overall, males in better condition had lower raw Photoshop hue values (Figure 3A). However, one morph-yellow-contrasted markedly against the rest of the morphs by showing a positive relationship between body condition and Hue data $(\beta=1.21 \pm 0.41$, SE, $P=0.008, n$ $=26$ ), and, thus, in effect showed a poorer, more brownish, less

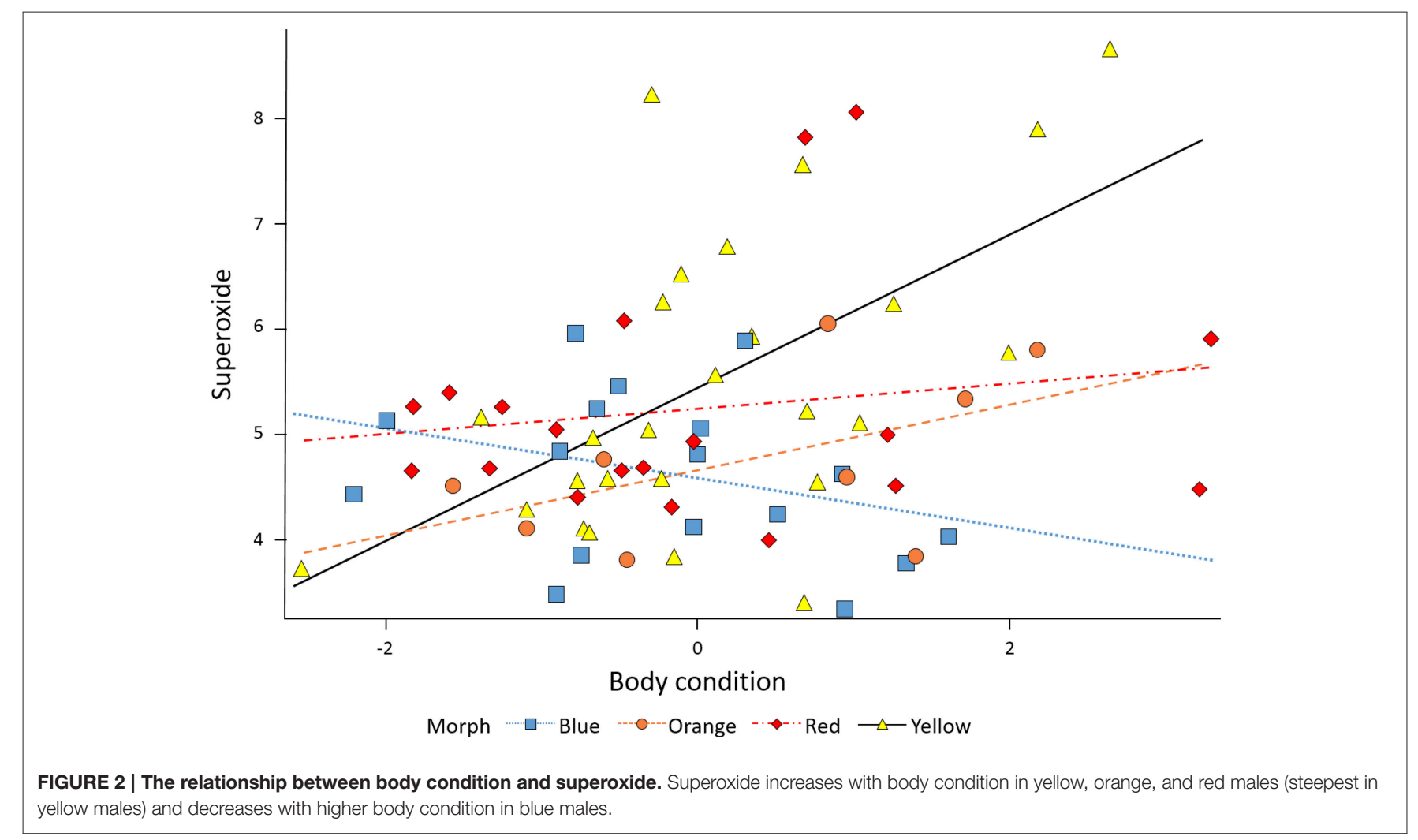


TABLE 1 | Proc Mixed, SAS 9.4 analysis of morph and condition interaction effects on superoxide levels.

\begin{tabular}{|c|c|c|c|c|c|c|}
\hline \multicolumn{7}{|c|}{ Solution for Fixed Effects } \\
\hline Effect & Revmorph & Estimate & $\begin{array}{c}\text { Standard } \\
\text { error }\end{array}$ & DF & $t$-Value & $\operatorname{Pr}>|t|$ \\
\hline Intercept & & 5.4485 & 0.2033 & 64 & 26.80 & $<0.0001$ \\
\hline Morph & BLUE & -0.8517 & 0.3263 & 64 & -2.61 & 0.0113 \\
\hline Morph & ORANGE & -0.7673 & 0.4116 & 64 & -1.86 & 0.0669 \\
\hline Morph & RED & -0.1844 & 0.3082 & 64 & -0.60 & 0.5518 \\
\hline Morph & YELLOW & 0 & - & - & - & - \\
\hline Condition (Cond) & & 0.7249 & 0.1818 & 64 & 3.99 & 0.0002 \\
\hline CondMorph & BLUE & -0.9566 & 0.3035 & 64 & -3.15 & 0.0025 \\
\hline Cond*Morph & ORANGE & -0.4127 & 0.3299 & 64 & -1.25 & 0.2155 \\
\hline Cond*Morph & RED & -0.6059 & 0.2400 & 64 & -2.52 & 0.0141 \\
\hline CondMorph & YELLOW & 0 & - & - & - & - \\
\hline
\end{tabular}

Type 3 Tests of Fixed Effects

\begin{tabular}{lcccc}
\hline Effect & Num DF & Den DF & F-Value & Pr $>\boldsymbol{F}$ \\
\hline Morph & 3 & 64 & 2.90 & 0.0418 \\
Cond & 1 & 64 & 4.44 & 0.0390 \\
Cond*Morph & 3 & 64 & 3.82 & 0.0139 \\
\hline
\end{tabular}

vivid, yellow coloration (Figure 3B). The morphs may overlap slightly in hue however, in Photoshop the hue value takes into account the Chroma (or color).

\section{DISCUSSION}

Our results paint a complex picture of morph-specific differences in levels of superoxide (and the potential for oxidative stress) and its relationship to body condition and coloration. Coloration is primarily generated by carotenoid and pteridine pigments in Australian Painted dragons and evidence suggests that the allocation or absorption of these two pigments might be connected with ROS biology and the antioxidant machinery (Oettl and Reibnegger, 2002; Costantini et al., 2008; Tomášek et al., 2016). Thus, individuals who constantly are able to allocate substantial amounts of these pigments to maintain skin pigmentation during the breeding season might not be able to use them as antioxidants and would suffer from increased levels of oxidative stress. Olsson et al. (2012) have previously shown in this species that the rate of color fading was not related to the overall ROS levels (non-specific ROS) but was negatively correlated with superoxide levels and color fading was prevented by supplementation with a superoxide dismutase mimetic.

Our analyses were designed to quantify among-morph differences in the relationships between condition and two response traits, level of superoxide (to capture a potential oxidative stress), and coloration (to assess robustness of coloration in terms of these ROS costs from a handicap perspective). A practical difficulty in the study of conditiondependent traits is that condition is not directly quantifiable (Green, 2001; Hill, 2011; Milenkaya et al., 2015). Conceptually,
TABLE 2 | Proc Mixed analysis in SAS 9.4 of effects on Inverse Hue at the end of the study period.

\begin{tabular}{llccccc}
\hline \multicolumn{7}{c}{ Solution for Fixed Effects } \\
\hline Effect & Morph & Estimate & $\begin{array}{c}\text { Standard } \\
\text { error }\end{array}$ & DF & $\boldsymbol{t}$-Value & Pr $>|\boldsymbol{t}|$ \\
\hline Intercept & & 0.007397 & 0.001217 & 33.7 & 6.08 & $<0.0001$ \\
Morph & BLUE & 0.000641 & 0.000435 & 61.3 & 1.47 & 0.1459 \\
Morph & ORANGE & -0.00005 & 0.000549 & 61.8 & -0.09 & 0.9309 \\
Morph & RED & 0.000705 & 0.000469 & 61 & 1.50 & 0.1383 \\
Morph & YELLOW & 0 & - & - & - & - \\
Condition (Cond) & & -0.00053 & 0.000247 & 62.5 & -2.14 & 0.0359 \\
Cond*Morph & BLUE & 0.001003 & 0.000415 & 61.3 & 2.42 & 0.0187 \\
Cond*Morph & ORANGE & 0.000961 & 0.000427 & 61.4 & 2.25 & 0.0281 \\
Cond*Morph & RED & 0.000803 & 0.000309 & 61.3 & 2.60 & 0.0117 \\
Cond*Morph & YELLOW & 0 & - & - & - & - \\
InvHue, Start & & 0.6555 & 0.05010 & 61 & 13.08 & $<0.0001$ \\
& & & & & &
\end{tabular}

Type 3 Tests of Fixed Effects

\begin{tabular}{lcccc}
\hline Effect & Num DF & Den DF & $\boldsymbol{F}$-Value & Pr $>\boldsymbol{F}$ \\
\hline Revmorph & 3 & 61.4 & 1.35 & 0.2670 \\
Cond & 1 & 62.6 & 1.09 & 0.3013 \\
Cond"Morph & 3 & 61.3 & 3.38 & 0.0237 \\
Inv Hue, Start & 1 & 61 & 171.20 & $<0.0001$
\end{tabular}

Lower Inverse Hue values in Photoshop suggests "poorer" color, e.g., more "brownish" yellow.

condition depends on the genetic background and gene by environment interactions that allow for physiological efficiency and the capacity to manage environmental stress (Hill, 2011; Bonduriansky et al., 2015). A body of evidence linking BCI and other physiological parameters would allow us to fully understand the costs of condition-dependent trait expression (Hill, 2011; Isaksson et al., 2011). Furthermore, studying the genetics linking indices of condition to sexually selected traits is easiest in lab models (e.g., Drosophila; Bonduriansky et al., 2015), which will rarely allow for evolutionary inferences in natural habitats and free-living populaitons. This is where colorpolymorphic species may be convenient models.

Polymorphic species are conspicuous because they have obvious differences in physical features that are "skin deep" (e.g., pattern and color), but they also often exhibit different reproductive strategies that are the product of correlated selection on behaviors and physiology. The relationship between superoxide levels and BCI depended on morph, and was strongest in yellow morphs suggesting a complex link between resource allocation and superoxide (Monaghan et al., 2009; Hill, 2011; Garratt and Brooks, 2012). Red morphs showed the weakest relationship between $\mathrm{BCI}$ and superoxide (i.e., slope closest to 0; see Figure 2), suggesting that the relationship between resource allocation toward or away from particular physiological processes is dependent on the genetic background of the individual (Tomkins et al., 2004), this is consistent with the genic capture hypothesis. 


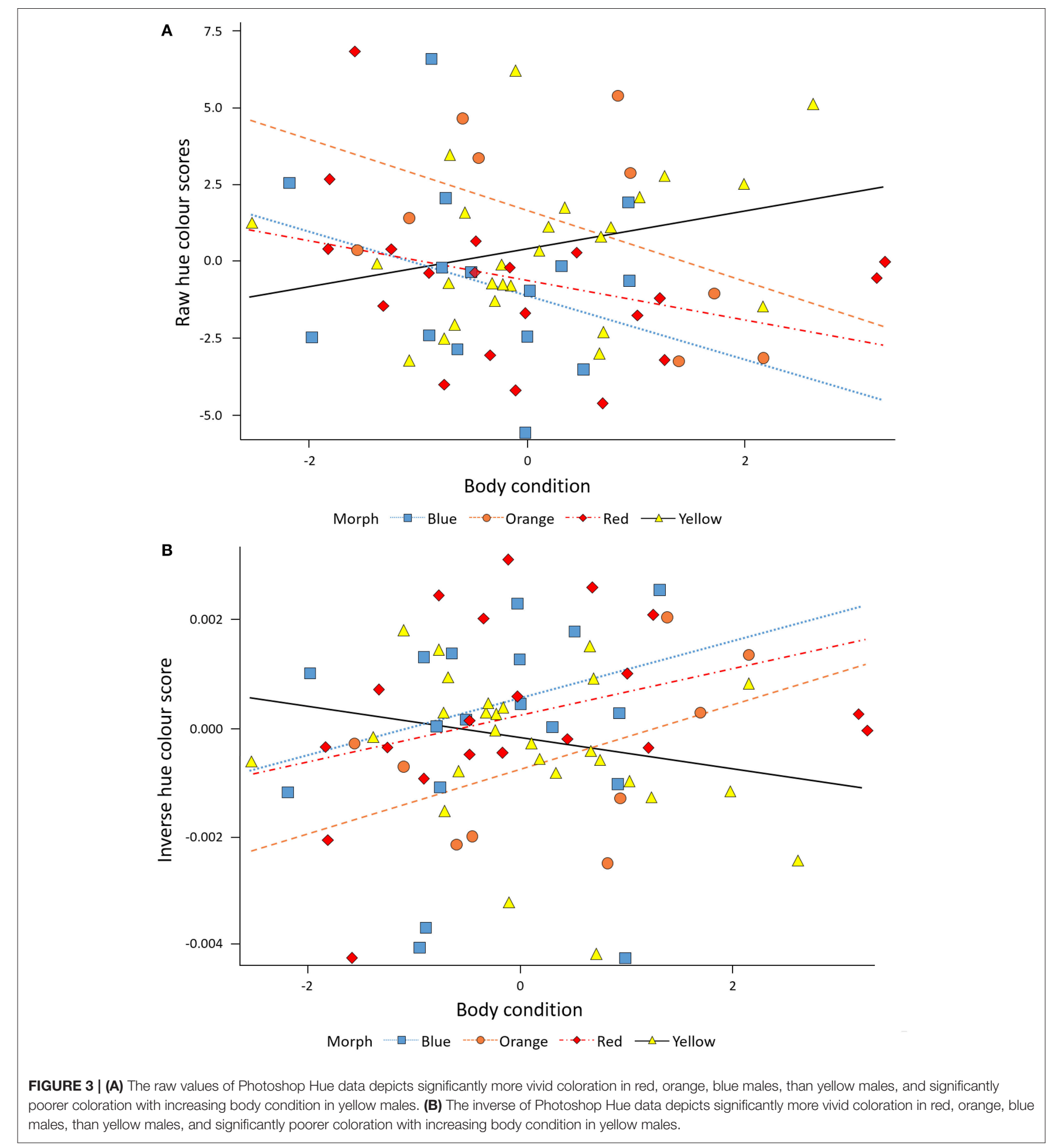

Contrary to what we might predict based on the testosteronemediated oxidation hypothesis and our previous results showing that red morphs have higher testosterone (Olsson et al., 2007b), the red morphs had lower superoxide levels and were better able to maintain their coloration than yellow morphs. Red morphs had the weakest relationship between superoxide levels and $\mathrm{BCI}$, yet are more aggressive and have higher testosterone than yellow morphs (Healey et al., 2007; Olsson et al., 2007b). This is, however, consistent with a selection history that has optimized mitochondrial function to reduce superoxide production in the morph with higher aggression. 
The yellow morphs, the least aggressive morph, had the poorest color maintenance relative to their body condition, and this result is probably explained by yellow morphs also exhibiting the strongest direct relationship between superoxide levels and BCI. Yellow morphs may therefore be shunting resources away from color maintenance (e.g., carotenoids and other nutrients, or simply energy) to other aspects of physiological condition or reproduction [sensu 8], while red morphs may prioritize color expression. Yellow morphs may also have a selection history with weaker selection on color-maintenance and the concomitant selection to optimize mito-nuclear interactions that would reduce superoxide production. Red morphs, conversely, are more aggressive and win head to head contests with yellow morphs (Healey et al., 2007). Therefore, there are proven benefits to red morphs in signaling their "redness," and thus if resources are available, it pays to invest in head-color maintenance (and the genetic background to do so), potentially through an increase in endogenous antioxidant expression, which may explain why BCI had a weaker effect on color maintenance in this morph.

Yellow morphs have a reproductive strategy that relies on post-copulatory sexual selection, i.e., sperm competition (Olsson et al., 2009b), which may relax selection on color maintenance in favor of testicular development and perhaps sperm performance (e.g., longevity). Higher ROS is known to negatively affect sperm performance (Aitken et al., 1989; Dowling and Simmons, 2009; Almbro et al., 2011), so it would seem paradoxical for the morph that relies on a reproductive tactic centerd on sperm competition to maintain higher superoxide as we saw here. Although some studies support a positive correlation between sperm performance and bright coloration (e.g., Evans et al., 2003; Helfenstein et al., 2010), the overall relationship between secondary sexual characters and sperm quality is not significant across taxa (meta-analytic review; Mautz et al., 2013). Of course, oxidative status cannot adequately be represented by a single measure, and it is possible that yellow morphs in this study upregulate endogenous antioxidants which may be protective of sperm function. Nevertheless, it is unclear whether superoxide measured in the blood is related to sperm performance in this species as it is in other lab-raised species (Veskoukis et al., 2009), and this merits further investigation.

We do not fully understand the behavioral ecology and reproductive tactics of blue- and orange morphs due to their recent invasion into this population (Olsson et al., 2007a), so we can only speculate about them. Nevertheless, blue morphs appear to be like the red morphs in some aspects of their biology, including aggressiveness and morph-specific telomere dynamics (Rollings et al., under review). Orange morphs seem to be

\section{REFERENCES}

Aitken, R. J., Clarkson, J. S., and Fishel, S. (1989). Generation of reactive oxygen species, lipid peroxidation, and human sperm function. Biol. Reprod. 41, 183-197. doi: 10.1095/biolreprod41.1.183

Almbro, M., Dowling, D. K., and Simmons, L. W. (2011). Effects of vitamin $\mathrm{E}$ and beta-carotene on sperm competitiveness. Ecol. Lett. 14, 891-895. doi: 10.1111/j.1461-0248.2011.01653.x intermediate to red- and yellow morphs in some aspects of their biology (Healey and Olsson, 2008, 2009). Blue morphs have not been previously characterized (because of their recent emergence in our study population), but appear to lack yellow-red skin pigmentation. One explanation to their starkly contrasting relationship to superoxide compared to the other morphs is that blue morphs allocate pigments as systemic antioxidants, which may explain the co-occurrence of no skin pigmentation and low superoxide levels with increasing body condition. Interestingly, blue morphs are also the only males for which color scores are uncorrelated between early and late in the season, as if pigments were never dermally deposited and hence may be why they do not exhibit any depletion or fading effects through time.

Although our conclusions are necessarily tentative, this study points us toward the utility of color-polymorphic species for studying intraspecific condition-dependence as it relates to alternative reproductive strategies and sexual selection in the wild (Wellenreuther et al., 2014). Visually identifying an individual's genotype in the wild is useful in field studies of sexual selection, and thus may prove valuable for studies of genic capture in nature. We suspect that investigation into the reproductive biology and strategies of these morphs will reveal similar trends.

\section{ETHICS STATEMENT}

Animals were collected under a permit issued by NSW National Parks and Wildlife Service (SL100352) and experiments were conducted in accordance with University of Sydney ethics approval (AEC-2013/6050).

\section{AUTHOR CONTRIBUTIONS}

All authors listed, have made substantial, direct and intellectual contribution to the work, and approved it for publication.

\section{ACKNOWLEDGMENTS}

We thank the Australian Research Council (MO), the National Science Foundation (CRF), and The University of Sydney (MO, NR) for financial support, and Ernie Snaith for logistic support and Adele Haythornthwaite for administrative support.

\section{SUPPLEMENTARY MATERIAL}

The Supplementary Material for this article can be found online at: http://journal.frontiersin.org/article/10.3389/fevo. 2017.00001/full\#supplementary-material 
Bonilla, M. M., Zeh, J. A., and Zeh, D. W. (2016). An epigenetic resolution of the lek paradox. BioEssays. 38, 355-366. doi: 10.1002/bies.201500176

Bortolotti, G. R., Mougeot, F., Martinez-Padilla, J., Webster, L. M., and Piertney, S. B. (2009). Physiological stress mediates the honesty of social signals. PLoS ONE 4:e4983. doi: 10.1371/journal.pone.0004983

Chandler, C. H., Ofria, C., and Dworkin, I. (2013). Runaway sexual selection leads to good genes. Evolution 67, 110-119. doi: 10.1111/j.1558-5646.2012.01750.x

Costantini, D. (2008). Oxidative stress in ecology and evolution: lessons from avian studies. Ecol. Lett. 11, 1238-1251. doi: 10.1111/j.1461-0248.2008.01246.x

Costantini, D. (2010). Redox physiology in animal function: the struggle of living in an oxidant environment. Curr. Zool. 56, 687-702.

Costantini, D. (2014). Oxidative Stress and Hormesis in Evolutionary Ecology and Physiology: A Marriage between Mechanistic and Evolutionary Approaches. New York, NY: Springer Science + Business Media.

Costantini, D., Fanfani, A., and Dell'omo, G. (2008). Effects of corticosteroids on oxidative damage and circulating carotenoids in captive adult kestrels (Falco tinnunculus). J. Comp. Physiol. B 178, 829-835. doi: 10.1007/s00360-0080270-z

Cotton, S., Fowler, K., and Pomiankowski, A. (2004). Do sexual ornaments demonstrate heightened condition-dependent expression as predicted by the handicap hypothesis? Proc. R. Soc. Lond. B Biol. Sci. 271, 771-783. doi: 10.1098/rspb.2004.2688

Dowling, D. K., and Simmons, L. W. (2009). Reactive oxygen species as universal constraints in life-history evolution. Proc. R. Soc. B Biol. Sci. 276, 1737-1745. doi: 10.1098/rspb.2008.1791

Evans, J. P., Zane, L., Francescato, S., and Pilastro, A. (2003). Directional postcopulatory sexual selection revealed by artificial insemination. Nature 421 , 360-363. doi: 10.1038/nature01367

Folstad, I., and Karter, A. J. (1992). Parasites, bright males, and the immunocompetence handicap. Am. Nat. 139, 603-622. doi: 10.1086/285346

Garratt, M., and Brooks, R. C. (2012). Oxidative stress and condition-dependent sexual signals: more than just seeing red. Proc. R. Soc. B Biol. Sci. 279, 3121-3130. doi: $10.1098 /$ rspb.2012.0568

Green, A. J. (2001). Mass/length residuals: measures of body condition or generators of spurious results? Ecology 82, 1473-1483. doi: 10.1890/00129658(2001)082[1473:MLRMOB]2.0.CO;2

Grunst, A. S., Rotenberry, J. T., and Grunst, M. L. (2014). Age-dependent relationships between multiple sexual pigments and condition in males and females. Behav. Ecol. 25, 276-287. doi: 10.1093/beheco/art124

Hamilton, W. D., and Zuk, M. (1982). Heritable true fitness and bright birds: a role for parasites? Science 218, 384-387. doi: 10.1126/science.7123238

Healey, M., and Olsson, M. (2008). Territory acquisition in a polymorphic lizard: an experimental approach. Austr. Ecol. 33, 1015-1021. doi: 10.1111/j.1442-9993.2008.01871.x

Healey, M., and Olsson, M. (2009). Too big for his boots: Are social costs keeping condition-dependent status signalling honest in an Australian lizard? Austr. Ecol. 34, 636-640. doi: 10.1111/j.1442-9993.2009.01968.x

Healey, M., Uller, T., and Olsson, M. (2007). Seeing red: morph-specific contest success and survival rates in a colour-polymorphic agamid lizard. Anim. Behav. 74, 337-341. doi: 10.1016/j.anbehav.2006.09.017

Helfenstein, F., Losdat, S., Møller, A. P., Blount, J. D., and Richner, H. (2010). Sperm of colourful males are better protected against oxidative stress. Ecol. Lett. 13, 213-222. doi: 10.1111/j.1461-0248.2009.01419.x

Hill, G. E. (2011). Condition-dependent traits as signals of the functionality of vital cellular processes. Ecol. Lett. 14, 625-634. doi: 10.1111/j.1461-0248.2011.01622.x

Horrak, P., Sild, E., Soomets, U., Sepp, T., and Kilk, K. (2010). Oxidative stress and information content of black and yellow plumage coloration: an experiment with greenfinches. J. Exp. Biol. 213, 2225-2233. doi: 10.1242/jeb. 042085

Hung, H.-Y., and Li, S.-H. (2015). Brightness of melanin-based plumage coloration is a cue to oxidative stress in Himalayan Black Bulbuls (Hypsipetes leucocephalus nigerrimus). Avian Res. 6, 1. doi: 10.1186/s40657-015-0031-0

Huxley, J. (1955). Morphism and evolution. Heredity 9, 1-51. doi: $10.1038 /$ hdy.1955.1

Isaksson, C., Sheldon, B. C., and Uller, T. (2011). The challenges of integrating oxidative stress into life-history biology. Bioscience 61, 194-202. doi: 10.1525/bio.2011.61.3.5
Kodric-Brown, A., and Brown, J. H. (1984). Truth in advertising: the kinds of traits favored by sexual selection. Am. Nat. 124, 309-323. doi: 10.1086/284275

Kotiaho, J. S., LeBas, N. R., Puurtinen, M., and Tomkins, J. L. (2008). On the resolution of the lek paradox. Trends Ecol. Evol. 23, 1-3. doi: 10.1016/j.tree.2007.09.012

Lendvai, A. Z., Giraudeau, M., Nemeth, J., Bako, V., and McGraw, K. J. (2013). Carotenoid-based plumage coloration reflects feather corticosterone levels in male house finches (Haemorhous mexicanus). Behav. Ecol. Sociobiol. 67, 1817-1824. doi: 10.1007/s00265-013-1591-9

Lorch, P. D., Proulx, S., Rowe, L., and Day, T. (2003). Condition-dependent sexual selection can accelerate adaptation. Evol. Ecol. Res. 5, 867-881.

Mautz, B. S., Møller, A. P., and Jennions, M. D. (2013). Do male secondary sexual characters signal ejaculate quality? A meta-analysis. Biol. Rev. 88, 669-682. doi: 10.1111/brv.12022

McGraw, K. J., Mackillop, E. A., Dale, J., and Hauber, M. E. (2002). Different colors reveal different information: how nutritional stress affects the expression of melanin-and structurally based ornamental plumage. J. Exp. Biol. 205, $3747-3755$.

Milenkaya, O., Catlin, D. H., Legge, S., and Walters, J. R. (2015). Body condition indices predict reproductive success but not survival in a sedentary, tropical bird. PLOS ONE 10:e0136582. doi: 10.1371/journal.pone. 0136582

Monaghan, P., Metcalfe, N. B., and Torres, R. (2009). Oxidative stress as a mediator of life history trade-offs: mechanisms, measurements and interpretation. Ecol. Lett. 12, 75-92. doi: 10.1111/j.1461-0248.2008.01258.x

Nur, N., and Hasson, O. (1984). Phenotypic plasticity and the handicap principle. J. Theor. Biol. 110, 275-297. doi: 10.1016/S0022-5193(84)80059-4

Oettl, K., and Reibnegger, G. (2002). Pteridine derivatives as modulators of oxidative stress. Curr. Drug Metab. 3, 203-209. doi: 10.2174/1389200024605127

Oh, K. P., and Badyaev, A. V. (2006). Adaptive genetic complementarity in mate choice coexists with selection for elaborate sexual traits. Proc. R. Soc. B Biol. Sci. 273, 1913-1919. doi: 10.1098/rspb.2006.3528

Olsson, M., Healey, M., and Astheimer, L. (2007b). Afternoon T: Testosterone level is higher in red than yellow male polychromatic lizards. Physiol. Behav. 91, 531-534. doi: 10.1016/j.physbeh.2007.04.025

Olsson, M., Healey, M., Wapstra, E., and Uller, T. (2009a). Testing the quality of a carrier: a field experiment on lizard signalers. Evolution 63, 695. doi: 10.1111/j.1558-5646.2008.00569.x

Olsson, M., Healey, M., Wapstra, E., Schwartz, T., Lebas, N., and Uller, T. (2007a). Mating system variation and morph fluctuations in a polymorphic lizard. Mol. Ecol. 16, 5307-5315. doi: 10.1111/j.1365-294X.2007.03578.x

Olsson, M., Schwartz, T., Uller, T., and Healey, M. (2009b). Effects of sperm storage and male colour on probability of paternity in a polychromatic lizard. Anim. Behav. 77, 419-424. doi: 10.1016/j.anbehav.2008.10.017

Olsson, M., Tobler, M., Healey, M., Perrin, C., and Wilson, M. (2012). A significant component of ageing (DNA damage) is reflected in fading breeding colors: an experimental test using innate antioxidant memetics in painted dragon lizards. Evolution 66, 2475-2483. doi: 10.1111/j.1558-5646.2012. 01617.x

Olsson, M., Wilson, M., Isaksson, C., and Uller, T. (2009c). Polymorphic ROS scavenging revealed by CCCP in a lizard. Naturwissenschaften $96,845-849$. doi: 10.1007/s00114-009-0530-0

Olsson, M., Wilson, M., Isaksson, C., Uller, T., and Mott, B. (2008). Carotenoid intake does not mediate a relationship between reactive oxygen species and bright colouration: experimental test in a lizard. J. Exp. Biol. 211, 1257-1261. doi: $10.1242 /$ jeb. 015065

Pomiankowski, A., and Moller, A. (1995). A resolution of the lek paradox. Proc. $R$. Soc. Lond. B Biol. Sci. 260, 21-29. doi: 10.1098/rspb.1995.0054

Pryke, S. R., and Griffith, S. C. (2006). Red dominates black: agonistic signalling among head morphs in the colour polymorphic Gouldian finch. Proc. R. Soc. Lond. B Biol. Sci. 273, 949-957. doi: 10.1098/rspb.2005.3362

Pryke, S. R., Astheimer, L. B., Buttemer, W. A., and Griffith, S. C. (2007). Frequency-dependent physiological trade-offs between competing colour morphs. Biol. Lett. 3, 494-497. doi: 10.1098/rsbl.2007.0213

Reinhart, M., Carney, T., Clark, A. G., and Fiumera, A. C. (2015). Characterizing male-female interactions using natural genetic variation in Drosophila melanogaster. J. Hered. 106, 67-79. doi: 10.1093/jhered/ esu076 
Rowe, L., and Houle, D. (1996). The lek paradox and the capture of genetic variance by condition dependent traits. Proc. R. Soc. Lond. B Biol. Sci. 263, 1415-1421. doi: $10.1098 / \mathrm{rspb} .1996 .0207$

Sinervo, B., and Lively, C. M. (1996). The rock-paper-scissors game and the evolution of alternative male strategies. Nature 380, 240-243. doi: $10.1038 / 380240 \mathrm{a} 0$

Slagsvold, T., and Lifjeld, J. T. (1992). Plumage color is a conditiondependent sexual trait in male pied flycatchers. Evolution 46, 825-828. doi: $10.2307 / 2409649$

Stephen Dobson, F., Nolan, P. M., Nicolaus, M., Bajzak, C., Coquel, A. S., and Jouventin, P. (2008). Comparison of color and body condition between early and late breeding king penguins. Ethology 114, 925-933. doi: 10.1111/j.1439-0310.2008.01545.x

Tomášek, O., Gabrielová, B., Kačer, P., Maršík, P., Svobodová, J., Syslová, K., et al. (2016). Opposing effects of oxidative challenge and carotenoids on antioxidant status and condition-dependent sexual signalling. Sci. Rep. 6:23546. doi: 10.1038/srep23546

Tomkins, J. L., Radwan, J., Kotiaho, J. S., and Tregenza, T. (2004). Genic capture and resolving the lek paradox. Trends Ecol. Evol. 19, 323-328. doi: 10.1016/j.tree.2004.03.029

Velando, A., Beamonte-Barrientos, R., and Torres, R. (2006). Pigment-based skin colour in the blue-footed booby: an honest signal of current condition used by females to adjust reproductive investment. Oecologia 149, 535-542. doi: $10.1007 /$ s00442-006-0457-5
Veskoukis, A. S., Nikolaidis, M. G., Kyparos, A., and Kouretas, D. (2009). Blood reflects tissue oxidative stress depending on biomarker and tissue studied. Free Radic. Biol. Med. 47, 1371-1374. doi: 10.1016/j.freeradbiomed.2009.07.014

von Schantz, T. B., Grahn, S., Hasselquist, M., and Wittzell, H. (1999). Good genes, oxidative stress and condition-dependent sexual signals. Proc. R. Soc. Lond. B Biol. Sci. 266, 1-12. doi: 10.1098/rspb.199 9.0597

Wellenreuther, M., Svensson, E. I., and Hansson, B. (2014). Sexual selection and genetic colour polymorphisms in animals. Mol. Ecol. 23, 5398-5414. doi: $10.1111 / \mathrm{mec} .12935$

Zahavi, A. (1975). Mate selection-a selection for a handicap. J. Theor. Biol. 53, 205-214. doi: 10.1016/0022-5193(75)90111-3

Conflict of Interest Statement: The authors declare that the research was conducted in the absence of any commercial or financial relationships that could be construed as a potential conflict of interest.

Copyright (c) 2017 Friesen, Wilson, Rollings, Sudyka, Whittington, Giraudeau and Olsson. This is an open-access article distributed under the terms of the Creative Commons Attribution License (CC BY). The use, distribution or reproduction in other forums is permitted, provided the original author(s) or licensor are credited and that the original publication in this journal is cited, in accordance with accepted academic practice. No use, distribution or reproduction is permitted which does not comply with these terms. 